\title{
Mothers' social regulatory language to young children in family settings*
}

$\left.\begin{array}{l}\text { TAMARA HALLE } \\ \text { MARILYN SHATZ }\end{array}\right\}$ University of Michigan

\section{ABSTRACT}

We investigate the language mothers use to regulate social conduct in family settings with their older (4- to 5-year-old) and younger (2-year-old) children. Samples of spontaneous conversations between British mothers and their children were collected over six months. Twenty-five percent of mothers' childdirected speech was social regulatory, with significantly more such language directed to younger children. Although the most common kind of regulatory language directed to both children was imperative mands used prescriptively, our data also suggest permission statements to younger children were used often to restrict activity, whereas permission statements to older children were used largely to permit activity. We discuss results with regard to maternal sensitivity to children's developmental differences, conversational constraints in family settings, and possible cultural influences on speech styles.

Acquiring an understanding of status relations and appropriate social conduct is a crucial part of social development. Children learn through interactions with others what behaviours are considered appropriate for people of differential social status. One of the most effective ways of

The data on which this study is based were collected by Judy Dunn and Penny Munn. We thank them for making the data available to us. We also wish to thank John Warner and J. E. Keith Smith for helpful statistical advice. This work was supported, in part, by NIH Training Grants 5 T32 HD07109-10 and 5 T32 HD07109-15 to the first author. Address for correspondence: Tamara Halle, Department of Psychology, 3433 Mason Hall, University of Michigan, Ann Arbor, MI 48109-1027, USA. 
conveying status relations and regulating social behaviour is through language. How socializing agents speak to a child, what they say and the notions they convey through their speech are likely to have a large impact on the socialization of the child. Although one can argue that all parental speech serves to socialize the child in one way or another, only a select portion of that language directly focuses on regulating social behaviour. Language used specifically to convey or establish social dynamics between individuals may be termed social regulatory language.

Previous studies have investigated children's understanding of social dynamics by examining authority or status relations among preschool peers (McGrew 1972, Strayer \& Strayer 1980, Vaughn \& Waters 1981). Children as young as four have an idea of the prevalent social organization in their culture, and they express status relations through their own language in pretend and free-play situations (Andersen 1977, 1978, Corsaro 1979, Garvey 1975) as well as during acts of negotiation and conflict resolution (Eisenberg \& Garvey 1981, Gearhart 1983, Newman 1978). However, before children can use social regulatory language spontaneously and strategically, they must learn what types of language are appropriate and acceptable under particular circumstances. Normally, the acquisition of the social knowledge governing language use begins at home where children receive their first social contacts. Understanding the dynamics of social relations within the family could be a useful precursor to understanding social hierarchies in society. One purpose of this study is to examine the language on which children might build their ideas about social relations: we investigate mothers' use of social regulatory language to young children.

Although there have been numerous studies examining maternal linguistic input to children acquiring language, only a few studies have focused on social regulatory language (Jones \& Adamson 1987, Munn 1990), and none to our knowledge has looked at mothers' differential use of such language to older (fully verbal) and younger (languagelearning) children within the same family. It is unclear whether mothers are consistent in their regulatory language to children differing in cognitive, social and linguistic levels of development, or whether they adjust to the level of the addressee, even in the presence of the other child. By examining the mothers' language over time, we can assess not only the consistency but also the stability of the linguistic input about social conduct and control directed to children of disparate ages and abilities. Specifically, we examine the amount and type of maternal social regulatory language used toward older and younger children within the same family over the course of half a year. 


\section{Social regulatory language}

We define social regulatory language as language used to establish, exercise, maintain or explain social order. Social regulatory language (a) permits or prohibits activity or otherwise encourages someone to do some action or stop some action; (b) is used to request or negotiate access to resources; or (c) states or explains one's right to control resources or activities.

Sometimes it is obvious when language is being used to do one of the above-mentioned tasks. At other times, it is necessary to take account of the conversational and situational context in which the language is spoken. The maternal utterances identified as social regulatory were selected from larger natural language transcripts on the basis of these considerations.

Types of regulatory language. In this study, we examine the frequency of different types of maternal regulatory language in terms of linguistic form, reference (what the utterance is about), and function (what interactional work the utterance does). We include directives such as imperatives ('Shut the window'), question-directives ('Why don't you shut the window?'), and indirect directives such as prompts to action ('You can do that') that encourage a listener to perform or not perform an action. Also included are statements of fact justifying authority ('Hey, I'm the mother here!') or control of resources ('That's mine') that deal with power, possession rights and roles. We also consider statements of permission and obligation because mothers may use them in conversation with their children to control behaviour and negotiate access to resources.

Mitigated speech. Speakers often use less direct forms of speech to get what they want from others (Olson 1980); they mitigate their speech. Mitigated, or polite, speech is an appropriate way for speakers of lower status to indicate deference to higher-status listeners. Also, Brown \& Levinson (1978) predict that familiar interactors would be less polite to one another than unfamiliar interactors. Nevertheless, regardless of status or level of familiarity, speakers sometimes use mitigated speech because of social convention. For example, even among familiars, it is considered more appropriate to say, 'Can I have a look at that?' than 'Give that to me.' One question is how much mitigated speech occurs in the home, where parents are familiar and salient authority figures, and social conventions are likely to be discussed and modelled. Hence, we assess the prevalence of mitigated speech in mothers' regulatory 
talk to young children. Of particular interest is whether mothers mitigate their speech more towards younger or older children.

\section{Communication between a mother and her children}

For families with more than one child, conversations between mother and child often take place in the presence of a sibling. Despite its ecological validity, the configuration of mother-child-sibling has received little empirical attention, especially in language-socialization research. Several studies have looked at language use in family settings (Dunn \& Munn 1985, Jones \& Adamson 1987, Munn 1990). However, in all of these studies, the focus has been not on a direct comparison of maternal speech to older and younger children within a family but on the younger, language-learning child. For example, in their examination of family conflict situations, Dunn \& Munn (1985) found that mothers and older siblings make explicit comments about transgressions of social rules to children as young as 18 months. They contend that family members are responding to the young child's growing interest in and understanding of permitted family behaviour and social rules. Munn (1990) found no change in the frequency of control episodes directed by mothers to younger children over the course of the child's third year of life. However, mothers did become more resistant to their two-year-olds' demands.

Jones \& Adamson (1987) examined mothers' speech to 20-montholds in both dyadic (mother-child) and triadic (mother-child-sibling) settings. They found that in mothers' speech directed to younger children, the relative amounts of social regulatory,' referential, and metalingual speech were similar in the dyadic and triadic free play situations. However, the total amount of younger child-directed speech decreased significantly when an older sibling was present. They also found that the triadic setting caused an increase in the younger child's use of social regulatory language, and that the toddler-directed speech of the older, preschool sibling was overwhelmingly social regulatory in nature. This finding suggests that, overall, there is considerable social regulatory language in family settings, but it is unclear how mothers apportion their social regulatory language between children who use it frequently to one another.

Dunn \& Shatz (1989) found that children in their third year of life often make relevant intrusions into conversations between their mothers

[1] In general, Jones and Adamson (1987) selected for analyses the same sorts of utterances that were of interest to us. However, the selection criteria were not identical. 
and an older sibling, thereby indicating that young children pay attention to language spoken in their presence even if that language is not necessarily directed to them. One implication of this finding is that observing the socialization of siblings may itself be a socializing force for the young child; hence, it is important to examine the type of language directed to an older sibling while a younger child is present. The present study's inclusion of and focus on mother-sibling exchanges, as well as those between mother and toddler, allow us to compare mothers' use of regulatory language to children of differing ages and to consider possible differences between what the young, language-learning child hears addressed to self and to other.

Mothers' behaviour toward siblings of different ages. Scarr \& McCartney (1983) argue that with increasing age, children elicit qualitatively different treatment from parents and others. Indeed, Dunn, Plomin \& Daniels (1986) report significant differences in maternal behaviour to the same child at 12 months and 24 months of age. Unsurprisingly, then, studies of maternal treatment of differentaged children have found differences in maternal social, affectionate and caretaking behaviour (Jacobs \& Moss 1976), as well as differences in levels of responsiveness and intrusiveness (Bryant \& Crockenberg 1980) towards first-born and later-born children. Analyses from these studies are based primarily on non-verbal behaviours. Studies reporting differences in maternal linguistic behaviour to different-aged children are in the literature as well, but they have mainly examined changes in formal properties such as mean length of utterance and sentence complexity (see Bellinger 1980). For example, there is evidence that mothers' speech to two-year-olds is simpler and more redundant than their speech to ten-year-olds (Snow 1972). Empirically, it is still an open question how much the pragmatic or social characteristics of maternal language may also change depending on the age of the addressee.

Of specific interest to us is whether mothers use language differently towards two-year-olds versus four-year-olds when attempting to address social regulatory issues. It has been noted that issues of control become more prevalent in interactions with two-year-olds (Dunn 1988, Munn 1990). Because they are beginning to practice asserting their autonomy (Shatz 1994), two-year-olds may be more likely than older children to exhibit behaviour which in turn elicits mothers' regulatory language. Thus, the salience of authority issues for two-year-olds may affect how frequently mothers use regulatory language in conversation with their young children. Dunn et al. (1986) argue that differential maternal treatment of siblings of different ages is most likely a 
response to perceived differences in the abilities, needs and demands of different-aged children. Based on what we know about the different capabilities of two-year-olds and four-year-olds, we would expect mothers to adjust their regulatory language (e.g., how they phrase this language, or what notions they convey with it) depending on the age of their child. At least this should be so for dyadic interactions between mother and child. It is harder to predict maternal speech behaviour with a sibling present. On the one hand, the age or social competence of the addressee may influence maternal regulatory language despite the presence of another child. On the other hand, the opportunity to express social regulatory principles accessible to both children, regardless of addressee, may mediate the tendency to adjust to one child's age or level of competence.

\section{Questions under investigation}

Our first concern is to describe the nature and frequency of maternal social regulatory language. Included in our description will be documentation of the forms and functions of mothers' social regulatory language and the degree to which regulatory language is mitigated.

Our second concern is to determine the similarities and differences in maternal regulatory language addressed to children of different ages. Because issues of power and autonomy are more salient and problematic for the two-year-old (Dunn 1988, Munn 1990), we predict mothers will direct more regulatory language towards the younger child than the older child; the forms and functions of the language (as well as the degree of mitigation) may or may not be consistent across children within the family.

Our third concern addresses the stability of mothers' use of social regulatory language to individual children across time. Munn's (1990) study suggests mothers do not alter their 'control' language (in terms of topics discussed, ways controls are initiated, and ways conversations are structured) when addressing children during their third year of life. If mothers do not change their speech style to children who are in the process of rapidly developing linguistic skills, they should be even less inclined to alter their speech over time to an older child, whose growth in cognitive and linguistic skills may be less dramatic. We expect mothers' use of regulatory language to both older and younger children to be relatively stable over the half year examined.

\section{METHODS}

\section{Subjects}

The subjects were six British mothers with older (mean age $=51$ 
months at the beginning of the study, range $=42-62$ months) and younger (all 24 months at the beginning of the study) children. The mean age difference between siblings was 27 months (range $=18-38$ months). Four out of the 6 sibling pairs were same-sex ( 3 pairs of girls; 1 pair of boys), and 2 were mixed-sex pairs ( 1 pair in which the girl was younger, 1 in which the boy was younger). Thus, there were 4 girls and 2 boys in both the younger and older sibling positions. These same subjects participated in other studies on family communication and interaction (Dunn \& Shatz 1989, Munn 1990); no attempt was made during subject recruitment to balance the sibling pairs for gender. Two mothers worked part-time outside the house, and one mother was employed but worked at home. One mother was college educated. Three families were classified as professional/managerial; 2 families as white-collar; and 1 family as semi-skilled manual, according to the 1971 Census of Great Britain (Register General 1971). Health Visitors, a British social agency, aided in the recruitment of the families.

\section{Procedure}

The data were collected at four different time points: when the younger child was $24,26,28$, and 30 months old. Two home observations of one hour each were conducted at each time point on two separate days. This study was based on half of the collected data, usually the second day's one hour observation at each time point for each family. Each session was audiotaped by the same observer using a portable tape-recorder. In order to minimize intrusiveness, the observer visited the family at least once prior to conducting the first observation and began recording conversation 10 minutes after arriving for a session. Although the mother and two children were not necessarily all in the same room during the entire observation, over $80 \%$ of all speech recorded occurred with all three family members present (range $=80.1 \%-95.7 \%$ ). The mothers were instructed to continue with the normal, family routine as if the observer was not present. The observer made extensive context notes on the interactions. The audiotapes were transcribed by the observer soon after each observation session. Transcripts were checked against the audiotapes by the second author; conflicts were discussed and resolved.

\section{Data coding}

The basic unit of analysis was the social regulatory utterance. All maternal utterances that involved giving permission or commands, requesting or encouraging obedience or action, or stating one's right to grant, demand or request things or control activities were identified 
from each of the 24 transcripts. The entire transcript and context notes were both taken into consideration before deciding whether an utterance was indeed intended to negotiate or assert power or social control. Because only transcripts and not actual tapes were available for analysis, information on intonation was not directly available. However, indications of intonation were sometimes given in the context notes. The first author identified all social regulatory utterances. To assess reliability, a second coder examined five randomly selected transcripts (out of 24) for social regulatory utterances. Percent agreement between the two coders on identifying maternal social regulatory language was $97.3 \%$ (range $=93.5 \%-100 \%$ ). For the six mothers, 9,466 utterances in all were examined, 2,374 of which were identified as social regulatory (mean $=396$ utterances per hour-long transcript, range $=231-486$ utterances). Social regulatory utterances were then coded for the following characteristics.

Sentence form. The sentence form of regulatory utterances was coded as either imperative ('Stop that now!'), declarative ('It's my turn'), question ('Can I have a turn now?'), or tag question ('Stop that now, will you?').

Reference and function codes. We used two separate kinds of codes to reveal what social regulatory messages are like and how they function. For both kinds, coders used surrounding context to make coding designations for an utterance. However, the reference code weighed the actual language of the utterance heavily and designated what the utterance was about, whereas the function code focused on the interactive context and designated what work the utterance did in the interaction. Each utterance received one reference code and one function code.

As for reference codes, explicitly allowing, denying, or requesting permission ('You can turn it off'; 'No, you can't have the knife, I'm afraid'; 'Can Kim have the spoon now?'), were coded as permission. Authority statements which expressed requirements to perform or not perform an act ('You're going to have to go upstairs'; 'Well, you mustn't do it') as well as strong suggestions to perform an act ('You ought to throw that away') were coded as obligation. Direct demands and commands for action or stop-action ('Give me a cuddle'; 'Stop that') were grouped as mands. There were social regulatory utterances referring to rights ('No, it's Mummy's, thank you'), ability ('Can you open that?'), or desire ('Do you want to watch me?'; 'No. Don't really want that out'). Encouragements ('Come on') and attentionals ('Look'; 'Sarah!') when used to urge a child either to act or not to act were grouped together as explicit prompts. Instances of social regulatory language that could not be coded into one of these reference categories were coded as other. 
As for the function codes, strong attempts to influence the addressee $\supset$ do an act were coded as prescriptive ('Let's put it back in the closet'; Can you put that in the box, please?'). Attempts to prevent the addressee rom acting ('Don't break it, Jamie, please'), or warnings ('What did I ay about those wax crayons, Abbie?'), or reprimands ('Get your hands way from the stove!'), were coded as proscriptive. Requests for agreeaent and compliance, as well as suggestions for action or information, vere coded as requestive statements ('Can she have one?'; 'Can you pen this?'). Negotiations presented the addressee with alternatives 'You can do it now, or else you'll have to stop and do it later'). The ategory of explanation/justification included those statements whose unction was to give a rationale for or explain a state of affairs ('I want his'; 'That was mine'). Other social regulatory language which did not it these functions were grouped into the category of other.

To illustrate the use of the reference and function codes, consider the wo utterances 'No, you can't have that' and 'Well, you mustn't do hat.' Both serve the proscriptive function of restricting behaviour, but he first utterance would be coded as referring to permission and the econd as referring to obligation, based on the linguistic forms present n each utterance.

Mitigated speech. An utterance was coded as mitigated speech if it ontained politeness markers such as 'please', or phrases such as 'I hink' or 'maybe'. Hints, either in the form of questions ('Can you get lown now?') or declaratives ('The man wants a drink, Lionel'), used to rescribe or proscribe behaviour, were coded as mitigated speech. In ddition, prescriptives referring to joint action ('Let's sit down here, hall we?') were coded as mitigated speech. As with the reference and unction codes, the surrounding conversational context and context lotes were used to designate utterances as mitigated or not. In articular, the use of context helped capture mitigated utterances which lid not include politeness markers or references to joint action.

Restatement and addressee. Each social regulatory utterance was oded for whether it was a repetition or restatement of a regulatory Itterance that immediately preceded it. ${ }^{2}$ An example is the second Itterance in the sequence, 'Will you stop that?' 'I said stop that now!'.

2] Since two-year-olds have relatively short attention spans, it was unclear whether they would interpret repetitions of social regulatory language following several intervening utterances as restatements. We therefore coded restatements conservatively as those repetitions occurring immediately after the original utterance in the transcript. Indeed, mothers may have repeated even contiguous utterances because they thought their young listeners were not attentive. Because of this, we analyse the data both with and without the immediate restatements. 
Finally, each regulatory utterance was marked for whether the addressee was the older or younger child.

Table 1 gives four examples of how four different social regulatory utterances were coded using the coding categories described above.

TABLE 1. Examples of the application of coding categories to social regulatory utterances

\begin{tabular}{|c|c|c|c|c|}
\hline & Example 1 & Example 2 & Example 3 & Example 4 \\
\hline $\begin{array}{l}\text { Coding } \\
\text { Category }\end{array}$ & $\begin{array}{l}\text { 'She can use } \\
\text { it.' }\end{array}$ & $\begin{array}{l}\text { 'Can you find } \\
\text { the red?' }\end{array}$ & $\begin{array}{l}\text { 'Would you like } \\
\text { me to bite your } \\
\text { foot?' }\end{array}$ & $\begin{array}{l}\text { 'He can play his } \\
\text { own game.' }\end{array}$ \\
\hline Sentence Form: & Declarative & Question & Question & Declarative \\
\hline Reference: & Permission & Ability & Desire & Permission \\
\hline Function: & Prescriptive & Prescriptive & Proscriptive & Explan./Justif. \\
\hline Mitigated: & No & Yes & Yes & No \\
\hline Restatement: & No & No & Yes & No \\
\hline Addressee: & $\begin{array}{l}\text { Older child } \\
\text { (50 months) }\end{array}$ & $\begin{array}{l}\text { Younger child } \\
\text { ( } 24 \text { months) }\end{array}$ & $\begin{array}{l}\text { Younger child } \\
\text { ( } 24 \text { months) }\end{array}$ & $\begin{array}{l}\text { Older child } \\
\text { (56 months) }\end{array}$ \\
\hline
\end{tabular}

\section{Reliability of coding}

The first author identified maternal social regulatory utterances from all transcripts. A second coder independently examined a random selection of 5 of the 24 transcripts (20\%) and identified maternal utterances that were social regulatory in nature. Percent agreement between the two coders was $97.3 \%$ (range $=93.5 \%-100 \%$ ). Disagreements were reconciled.

For the subsequent coding categories, two coders independently coded an average of 51 social regulatory utterances from each of 6 of the 24 transcripts used in the study (range $=37-89$ utterances). The parts of the six transcripts were randomly chosen from the six families and four time points under analysis. The coders reached an average reliability of $87 \%$ on all types of codes mentioned above (mean range $=$ $76 \%-99.5 \%$ ). All disagreements in coding were discussed and reconciled by the two coders. Fifteen of the transcripts were fully coded by one coder, and nine were fully coded by the second coder. The first author verified the coding on all transcripts for the two kinds of codes that had accounted for the lowest reliability, the reference code ( $76 \%$ reliability) and the function code $(76 \%$ reliability). Disagreements on reference were mainly due to conflicts in assigning an utterance to the other category or to one of the meaningful categories. 
Whenever possible, an utterance in dispute was coded into a meaningful reference category. Disagreements on the function code were mainly due to conflicts on coding utterances as prescriptive versus either proscriptive ('Get that out of your mouth'), explanation/justification ('You need chalks for that'), or negotiations ('You can have one, but only one'). In all cases, the general context in which the utterance was spoken was re-examined to resolve the dispute.

\section{RESULTS}

\section{Explanation of analyses}

The frequency of mothers' social regulatory language becomes meaningful only when it is related to each mother's overall frequency of speaking within the hour-long speech sample from which it is drawn. For this reason, the relative (that is, proportional) frequency of social regulatory language was used in analyses instead of raw frequency counts. Proportional frequency scores were submitted to arcsine transformations before analyses were conducted in order to normalize the frequency distribution of potentially small proportional frequency counts (Rao 1973). Significance levels for the repeated measures analyses of variance (ANOVAs) were conservatively adjusted using the Greenhouse Geisser epsilon adjustment.

\section{Proportional frequency of maternal social regulatory language}

Twenty-five percent of the mothers' utterances directed toward their older and younger children was coded as social regulatory. The arcsine transformation of the proportion of maternal speech to each child that was regulatory was analysed in a 2 (Addressee) $\times 4$ (Time point) withinsubjects repeated measures ANOVA. ${ }^{3}$ Mothers directed relatively more social regulatory language towards the younger child $(M=33 \%)$ than they did towards the older child $(M=20 \%), F(1,5)=15.71, p<0.02$. Inspection of the data showed that mothers directed proportionately more social regulatory language to younger children than older children in 21 out of the 24 sessions; that is, almost $90 \%$ of the transcripts showed this pattern of maternal speech behaviour. The amount of regulatory language did not change significantly with time, nor was there a time by addressee interaction.

Eliminating restatements. The younger children received restatements

[3] Because of the small sample size, statistical analyses examining gender differences could not be performed. The mean overall proportion of social regulatory language directed to boys was $28.1 \%$ compared to $24.5 \%$ for girls. 
$15 \%$ of the time whereas the older children received restatements only $11 \%$ of the time (one-tailed $t(5)=2.23, p<0.05$ ). Thus, it is possible our finding of Addressee differences may have been a function of the fact that mothers had to repeat their social regulatory utterances more often to their younger children. To test the integrity of the Addressee finding, we performed a second 2 (Addressee) $\mathrm{x} 4$ (Time point) repeated measures ANOVA, this time excluding restatements of initial social regulatory utterances. Even when restatements were excluded, a larger proportion of mothers' speech to their younger child was social regulatory $(M=25 \%)$ than was speech to their older child $(M=$ $18.6 \%), F(1,5)=14.49, p<0.02$. This pattern existed for 18 out of the 24 sessions under investigation; that is, $75 \%$ of the transcripts showed mothers directing more initial social regulatory utterances to the younger than to the older child. No other significant effects were found.

\section{The characteristics of social regulatory language}

Sentence form. Because all social regulatory utterances fell into one of the four sentence form categories (i.e., imperatives, declaratives, questions and tag questions), an analysis of variance cannot reveal main effects for addressee or time but is still a valid test for differences in the distribution of sentence modes used and any interactions between sentence form and addressee or time. A 2 (Addressee) $\times 4$ (Time) $\times 4$ (Sentence form) repeated measures ANOVA revealed a main effect of sentence form, $F(3,15)=361.79$, Greenhouse Geisser $p<0.0001$. Post hoc Bonferroni $t$-tests revealed that imperatives were significantly more frequent than all other utterance modes, comprising $65.5 \%$ of mothers' regulatory language to their children, $p<0.01$. In addition, declaratives (22.2\% of mothers' regulatory language) were used significantly more than tag questions ( $1.6 \%$ of mothers' regulatory language), $p<0.05$. Social regulatory language took the form of questions $10.7 \%$ of the time. No significant interaction effects were found.

Reference code. Table 2 shows the mean proportion of maternal regulatory language to each child distributed across the various categories of the reference code. A 2 (Addressee) $\times 4$ (Time point) $\times 7$ (Reference type) repeated measures ANOVA on the transformed proportions - analysing all categories except other - revealed a main effect for reference type, $F(6,30)=83.14$, Greenhouse Geisser $p<$ 0.0001 . Bonferroni $t$-tests revealed that mothers used regulatory language as mands significantly more frequently than any other type $(M=53 \%), p<0.01$. Social regulatory language expressed rights significantly less frequently than all other types except ability, $p<0.05$. In addition, mothers' social regulatory language expressed ability less 
than prompts $(p<0.01)$ or permission $(p<0.05)$. No other significant effects were found, indicating that reference did not differ by addressee or time.

TABLE 2. Distribution (in mean percent of total regulatory utterances) of the reference types in maternal social regulatory language

\begin{tabular}{|c|c|c|c|c|c|c|c|c|}
\hline \multirow[t]{2}{*}{ Child addressee } & \multicolumn{8}{|c|}{ Types of reference } \\
\hline & Permission & Obligation & Mand & Rights & Ability & Desire & Prompt & Other \\
\hline Younger & $\begin{array}{l}4.55 \\
(2-6)\end{array}$ & $\begin{array}{c}2.63 \\
(1-5)\end{array}$ & $\begin{array}{c}54.23 \\
(44-60)\end{array}$ & $\begin{array}{c}0.65 \\
(0-2)\end{array}$ & $\begin{array}{c}1.58 \\
(0-3)\end{array}$ & $\begin{array}{c}3.3 \\
(2-5)\end{array}$ & $\begin{array}{c}12.53 \\
(6-22)\end{array}$ & $\begin{array}{c}20.58 \\
(15-26)\end{array}$ \\
\hline Older & $\begin{array}{c}6.28 \\
(4-10) \\
\end{array}$ & $\begin{array}{c}4.65 \\
(1-7) \\
\end{array}$ & $\begin{array}{c}52.23 \\
(33-68) \\
\end{array}$ & $\begin{array}{c}0.4 \\
(0-2)\end{array}$ & $\begin{array}{c}2.8 \\
(0-5) \\
\end{array}$ & $\begin{array}{c}3.53 \\
(3-7)\end{array}$ & $\begin{array}{c}11.63 \\
(3-21)\end{array}$ & $\begin{array}{c}18.48 \\
(8-27) \\
\end{array}$ \\
\hline Mean & 5.42 & 3.64 & 53.23 & 0.53 & 2.19 & 3.42 & 12.08 & 19.53 \\
\hline
\end{tabular}

Note: Ranges appear in parentheses.

Functions of regulatory language. Table 3 shows the mean proportion of maternal regulatory language to each child distributed across the various function types. No regulatory language was classified into the miscellaneous other category, and therefore the total amount of regulatory language classified into clearly defined function categories equalled $100 \%$. Thus, an analysis of variance is unable to reveal main effects for addressee and time, but is a valid test of differences between function categories and of interactions between function and addressee or time. A 2 (Addressee) x 4 (Time point) x 5 (Function type) repeated measures ANOVA on the transformed proportions revealed a main effect for function type, $F(4,20)=92.26$,

TABLE 3. Distribution (in mean percent of total regulatory utterances) of the functions of maternal social regulatory language

\begin{tabular}{lcccccc}
\hline \multirow{2}{*}{ Child addressee } & \multicolumn{6}{c}{ Functions } \\
\cline { 3 - 7 } & Prescribe & Proscribe & Request & Negotiate & Explain/Justify & Other \\
\cline { 3 - 7 } Younger & 61.2 & 27.9 & 6.4 & 1.0 & 3.5 & 0 \\
& $(52-65)$ & $(22-37)$ & $(3-16)$ & $(0-3)$ & $(2-6)$ & \\
Older & 61.0 & 26.4 & 3.8 & 2.75 & 6.2 & 0 \\
& $(41-73)$ & $(15-45)$ & $(1-9)$ & $(0-4)$ & $(3-8)$ & \\
\hline Mean & 61.1 & 27.2 & 5.1 & 1.9 & 4.9 & 0 \\
\hline
\end{tabular}

Note: Ranges appear in parentheses. 
Greenhouse Geisser $p<0.0001$. Bonferroni $t$-tests indicated that prescribing was significantly more frequent than proscribing, $p<0.01$, and both prescribing and proscribing were significantly more frequent than requesting, explaining/justifying, or negotiating, $p<0.01$. No significant interactions with addressee or time were found.

Relation between the function and reference of social regulatory language. Table 4 is a descriptive presentation of the most frequently used functions of maternal regulatory language within each meaningful type of reference by addressee. Recall that mands were the most common reference type used by each mother to each child, and prescriptives were the most frequent function of social regulatory language. Thus, mothers primarily used direct language to get their children to do something. Prompts were also most often used to prescribe behaviour, as were mothers' statements referring to ability (e.g., 'See if you can find the letters then').

The majority of regulatory statements referring to obligations were used to explain or justify a state of affairs to both children ('You're supposed to sit on the chair'), as were the majority of mothers' rights statements ('That's mine'; 'I'm holding them'). Mothers' desire statements functioned most often as requestives to both children ('Want Mummy to do it?'). These data suggest that largely similar messages are conveyed through mothers' social regulatory language to older and younger children beyond the most prevalent reference (mand) and function (prescriptive) categories. However, the data in Table 4 also suggest differences in the ways mothers use social regulatory language to older and younger children.

Inspection of Table 4 suggests that mothers granted permission (prescriptive permissions) as often as they denied permission (proscriptive permissions) to their younger children, but were more likely to grant than deny permission to their older children. In fact, mothers' statements to their older children about permission functioned more often as explanations of a state of affairs ('Katie's never allowed to be He-man') than as proscribing activity ('You can't take that in there'). Although the majority of obligation utterances were used to explain a state of affairs, older children got almost as many prescriptive obligation statements ('You should do one for Grandpa, cos ... (he's) got to stay home') as they did explanatory obligation statements ('She has to go back to cook Meg's tea'). Younger children received roughly equal amounts of prescriptive and proscriptive obligation statements. In addition, mothers were almost as likely to refer to rights in order to restrict the younger child's behaviour ('You've had one and that's enough'; 'No, no, they're Daddy's') as they were merely to explain a 
state of affairs. Thus, a pattern of using proscriptive regulatory language more frequently to younger children and prescriptive regulatory language more frequently to older children was found for several reference categories. Although there were not enough instances of obligation, rights or desire utterances across mothers to conduct analyses, a Wilcoxon matched-pairs signed-ranks test on permissions showed that mothers directed proportionately more proscriptive permissions to younger children than to older children, $p<0.05$. These comparisons suggest that younger and older children are not treated identically by mothers. Further research is needed to confirm the suggested differences noted in these data.

TABLE 4. Most common functions within each reference type of maternal social regulatory language

\begin{tabular}{|c|c|c|c|c|c|c|c|}
\hline \multirow[t]{2}{*}{ Child addressee } & \multicolumn{7}{|c|}{ Types of reference } \\
\hline & Permission & Obligation & Mand & Rights & Ability & Desire & Prompt \\
\hline \multirow[t]{3}{*}{ Younger } & $\begin{array}{c}\text { Proscribe } \\
36.5 \%\end{array}$ & $\begin{array}{c}\text { Expl/Just } \\
48.8 \%\end{array}$ & $\begin{array}{c}\text { Prescribe } \\
74.9 \%\end{array}$ & $\begin{array}{c}\text { Expl/Just } \\
54.4 \%\end{array}$ & $\begin{array}{c}\text { Prescribe } \\
53.8 \%\end{array}$ & $\begin{array}{c}\text { Request } \\
59.3 \%\end{array}$ & $\begin{array}{c}\text { Prescribe } \\
73.8 \%\end{array}$ \\
\hline & $\begin{array}{c}\text { Prescribe } \\
33.8 \%\end{array}$ & $\begin{array}{c}\text { Prescribe } \\
26.8 \%\end{array}$ & $\begin{array}{c}\text { Proscribe } \\
23.5 \%\end{array}$ & $\begin{array}{c}\text { Proscribe } \\
45.5 \%\end{array}$ & $\begin{array}{c}\text { Request } \\
26.9 \%\end{array}$ & $\begin{array}{c}\text { Proscribe } \\
22.2 \%\end{array}$ & $\begin{array}{c}\text { Proscribe } \\
26.2 \%\end{array}$ \\
\hline & $\begin{array}{c}\text { Request } \\
18.9 \%\end{array}$ & $\begin{array}{c}\text { Proscribe } \\
22.0 \%\end{array}$ & & & & & \\
\hline \multirow[t]{4}{*}{ Older } & $\begin{array}{c}\text { Prescribe } \\
51.1 \%\end{array}$ & $\begin{array}{c}\text { Expl/Just } \\
47.4 \%\end{array}$ & $\begin{array}{c}\text { Prescribe } \\
75.5 \%\end{array}$ & $\begin{array}{c}\text { Expl/Just } \\
66.7 \%\end{array}$ & $\begin{array}{c}\text { Prescribe } \\
76.0 \%\end{array}$ & $\begin{array}{l}\text { Request } \\
51.7 \%\end{array}$ & $\begin{array}{c}\text { Prescribe } \\
68.4 \%\end{array}$ \\
\hline & $\begin{array}{c}\text { Expl/Just } \\
21.3 \%\end{array}$ & $\begin{array}{c}\text { Prescribe } \\
44.7 \%\end{array}$ & $\begin{array}{c}\text { Proscribe } \\
21.9 \%\end{array}$ & $\begin{array}{c}\text { Prescribe } \\
33.3 \%\end{array}$ & $\begin{array}{c}\text { Proscribe } \\
16.0 \%\end{array}$ & $\begin{array}{c}\text { Prescribe } \\
20.7 \%\end{array}$ & $\begin{array}{c}\text { Proscribe } \\
31.6 \%\end{array}$ \\
\hline & $\begin{array}{c}\text { Proscribe } \\
10.6 \%\end{array}$ & & & & & & \\
\hline & $\begin{array}{c}\text { Request } \\
10.6 \%\end{array}$ & & & & & & \\
\hline
\end{tabular}

Mitigation. In general, mothers mitigated their social regulatory language $16 \%$ of the time. A 2 (Addressee) $\times 4$ (Time) repeated measures ANOVA on the arcsine transformation of the percentage of mothers' regulatory language that was mitigated failed to reveal any main effects or interactions.

\section{DISCUSSION}

The home environment is the first arena in which children are exposed to authority relationships and the language that conveys them. To gain insight into the linguistic context for learning about social rules within 
the family, we examined how six mothers establish and maintain social control, and how they regulate the social behaviour of their children through language. We found that, overall, a quarter of our six British mothers' everyday speech to children aged 2 to 5 regulated social conduct and family dynamics. The frequency with which maternal social regulatory language occurs illustrates the importance of such language in child socialization.

In general, mothers directed more regulatory language to the younger child than the older child. This pattern endured across the course of a half year, even after eliminating restatements or repetitions of such language. It is likely that this frequency difference reflects the mothers' responses to their children's different developmental needs and concerns. The two-year-old's attempts to assert control or autonomy in given situations most likely elicits more regulatory language from the mother. This may also be the reason why two-yearolds received more repetitions of initial regulatory language than did their older siblings. A relatively short attention span also may contribute to the amount of social regulatory language directed towards two-year-olds.

More than half of mothers' regulatory language consisted of imperative mand statements which demanded that the children perform (or not perform) an act. Only $16 \%$ of the mothers' total regulatory speech was mitigated, and mothers did not mitigate their speech more to one child than the other. Thus, British mothers seem to favour the direct, imperative form of regulatory language over more 'polite', mitigated, or indirect forms. Moreover, there were no significant changes in mothers' regulatory language directed to either child over the half year under investigation. These findings suggest a pattern of consistency in mothers' use of social regulatory language towards their children, and parallel Munn's (1990) finding of stability of control episodes over the course of the child's third year of life.

In addition to mands (and prompts), mothers' social regulatory language also made reference to the concepts of permission, obligation, rights, ability, and desire. Although mothers referred to these concepts equally often when addressing both older and younger children, our data suggest some subtle differences in the messages conveyed by these statements. The differences seem to lie in the functions of the utterances within a given reference category. Permission statements most often directed to younger children were used to restrict access or activity, while most permission statements directed to older children functioned to permit access or activity. Similarly, younger children were more likely to hear obligation, rights and desire statements that 
proscribed behaviour, while older children were more likely to hear obligation, rights and desire statements that prescribed behaviour. The suggested differences in maternal regulatory language directed to older and younger children are in need of further investigation and confirmation.

Why was there so much consistency in the nature of a mother's social regulatory language despite the differences in her children's ages and cognitive, social and linguistic skills? There are two possible explanations. For one, mothers may be more direct in the presence of both younger and older children because they take the opportunity to structure social information for both children at the same time. Younger children may not be as successful at decoding subtle, indirect messages as older children, and mothers may seek a level of expression that is readily available to both children, even when the older child is the addressee. Also, keeping order in a multi-child situation may increase demands for more assertive forms of language. Given this explanation, we would expect that in dyadic situations, mothers might use a more direct style with younger children but a less direct style with slightly older children.

Alternatively, mothers may simply have a style of talking to toddlers and preschoolers about social conduct and authority relations that is not finely tuned to their age or cognitive-linguistic levels. Instead, maternal social regulatory speech styles used toward young children may be more broadly influenced by the child-rearing goals and values set by families and by their cultural communities. Given this explanation, we would expect that within-mother differences between dyadic and triadic situations would be small, but that there might be differences in maternal social regulatory styles across mothers and across cultural communities.

There are no studies that directly compare social regulatory language to different-aged children in both dyadic and triadic situations. However, a comparison of our findings to studies of dyadic situations suggests that mothers generally treat two-year-olds and older preschoolers much alike, at least with regard to directive use. Examining only directives and not all regulatory speech, Bellinger (1979) found that American mothers observed in dyadic laboratory playroom situations used imperatives for about half their directive speech to both two-year-olds and five-year-olds. Except for the most subtle and relatively rare indirect directives based on implication, all other forms of directives (i.e., conventional imperatives, interrogatives, and declaratives) were used in the same proportions to the differentaged children. Also, Shatz (1978a) found that mothers used indirect 
directives with two-year-olds in naturalistic dyadic situations, and that the children responded about as well to the indirect directives as to the direct ones. Although Shatz $(1978 b)$ cautioned that follow-up experimental work suggested the children's responses were likely based on unsophisticated response strategies, mothers nonetheless would have little reason to restrict their speech only to direct directives when they have witnessed their two-year-olds responding appropriately to more indirect language. Thus, the directness of the regulatory speech style may be determined more by the degree to which mothers feel the need to assert their authority over their children and less by the age and responsiveness of the child.

One factor influencing mothers' expressions of social regulation may be the child-rearing values and beliefs about parent-child relations held by the mothers' speech communities. Researchers studying adult-child interactions across cultures have noted that differences in parenting philosophy are reflected in the speech and behaviour of socializing agents (Barker \& Barker 1963, Clancy 1986, Devereux, Bronfenbrenner \& Rodgers 1969, Dunn \& Brown 1991, Matsumori 1981, Shatz 1991). For example, differing beliefs about generational equality and the nature of individual freedom may be responsible for the finding that American mothers use their modal expressions like can, may and must to refer more to intention and possibility than do German mothers when addressing their young children (Shatz, Grimm, Wilcox \& Niemeier-Wind 1989, Shatz 1991). Similarly, differing values placed on the individual's obligation to and role in the larger society may explain why Japanese mothers appeal to social norms when disciplining preschoolers, whereas American mothers refer more to personal feelings (Matsumori 1981).

Between communities which share the same linguistic system, even subtle differences in parenting attitudes may result in differences in linguistic and behavioural interaction styles. For example, although British and American patterns of child-rearing have much in common, differences have been observed as well. British parents were found to discuss behaviour more in terms of general societal norms for appropriate actions than did Americans, who focused more on individual rights (Dunn \& Brown 1991). Also, American parents used fewer negatives (Shatz 1991) and were considered more nurturent and less indulgent (Devereux et al. 1969) than were British parents. British adults have been described as adopting a more dominating style in their interactions with children compared to American adults (Barker \& Barker 1963).

It may be, then, that American mothers have a less direct regulatory 
style than the British mothers we observed. Although the comparison is not an apt one because of differences in focus and coding, it is nonetheless noteworthy that our British mothers had a higher percentage of imperatives among all their regulatory speech $(65.5 \%)$ than Bellinger's (1979) American mothers did just for their directive speech to two- and five-year-olds (48.2\%). In future work, it would be useful to examine directly social regulation styles in different cultural communities and among various speech partners. Such work promises to illuminate how parents convey their speech community's beliefs about rights and roles in the family and the larger society to young children.

The present study is noteworthy because it is a first attempt to characterize language which mothers use to regulate social conduct in the home, and which likely influences young children's understanding of social relations. Nonetheless, this study had several limitations. Its small sample size precludes us from generalizing our findings too widely. However, the fact that we found such strong patterns for the amount and type of social regulatory language used by this diverse sample of British mothers suggests that our findings shed some light on maternal socialization styles within the British culture, and perhaps on socializing language used in family settings in general. To be sure, more research should be done on larger samples of families, ideally cross-culturally, to examine these questions. Future research also might examine the possibility of gender differences in maternal regulatory language. Also, although surrounding context and context notes were useful in the identification and coding of maternal regulatory language, future investigations should determine how intonation influences the assessment of the function of an utterance. Finally, this study did not assess children's interpretations of social regulatory statements. Future research should directly investigate the connection between maternal social regulatory language and child reaction to that language.

\section{Conclusions}

This study examined children's early exposure to the notions of social relations and conduct through maternal socializing language. In the naturalistic family context, mothers directed more social regulatory language to two-year-olds than older children. The British mothers in this study primarily used social regulatory language in its most basic form: imperative, prescriptive mand statements. Despite much consistency and stability of maternal social regulatory language across addressee and time, our data also suggest there may be some subtle differences in the ways mothers use such language when addressing their older and 
younger children. It is unclear whether the character of the mothers' language is due to the situational constraints of the family context, the specifics of British child-rearing beliefs, or some combination of the two. Maternal regulatory language in a family setting may find some mean level of expression, but direct comparisons of dyadic and triadic situations should be made to investigate this possibility.

Based on what we know about the relatively short attention spans of two-year-olds and their concerns for establishing autonomy, our finding that mothers use more regulatory language to two-year-olds than to older children would likely be replicated on larger samples of subjects in England and other countries. Our findings about the linguistic style of social regulatory language cannot be universalized as readily. Further research is needed to illuminate any cultural variations which may exist in the forms and styles of maternal social regulatory language.

\section{REFERENCES}

Andersen, E. S. (1977). Young children's knowledge of role-related speech differences: a mommy is not a daddy is not a baby. Papers and Reports in Child Language Development, 13, 83-90.

_ (1978). Will you don't snore please?: directives in young children's role-play speech. Papers and Reports in Child Language Development, 15, 140-150.

Barker, R. G. \& Barker, L. S. (1963). Social actions in the behavior streams of American and English children. In R. G. Barker (ed.), The Stream of Behavior (New York: Appleton-Century-Crofts), 127-159.

Bellinger, D. (1979). Changes in the explicitness of mothers' directives as children age. Journal of Child Language, 6, 443-458.

(1980). Consistency in the pattern of change in mothers' speech: some discriminant analyses. Journal of Child Language, 7, 469-487.

Brown, P. \& Levinson, S. C. (1978). Universals in language usage: politeness phenomena. In E. N. Goody (ed.), Questions and Politeness: Strategies in Social Interaction (Cambridge: Cambridge University Press), 56-324.

Bryant, B. \& Crockenberg, S. (1980). Correlates and dimensions of prosocial behavior: a study of female siblings with their mothers. Child Development, $\mathbf{5 1}$, 529-544.

Clancy, P. M. (1986). The acquisition of communicative style in Japan. In B. B. Schieffelin \& E. Ochs (eds), Language Socialization Across Cultures (Cambridge: Cambridge University Press), 213 - 250.

Corsaro, W. A. (1979). Young children's conception of status and role. Sociology of Education, 52, 46-59.

Devereux, E. C., Bronfenbrenner, U. \& Rodgers, R. R. (1969). Child-rearing in England and the United States: a cross-national comparison. Journal of Marriage and the Family, 31, 257-270.

Dunn, J. (1988). The Beginnings of Social Understanding (Cambridge, MA: Harvard University Press).

Dunn, J. \& Brown, J. (1991). Becoming American or English? Talking about the social world in England and the United States. In M. H. Bornstein (ed.), Cultural Approaches to Parenting (Hillsdale, N J: Lawrence Erlbaum), 155-172. 
Dunn, J., \& Munn, P. (1985). Becoming a family member: family conflict and the development of social understanding in the second year. Child Development, 56, $480-492$.

Dunn, J. F., Plomin, R. \& Daniels, D. (1986). Consistency and change in mothers' behavior toward young siblings. Child Development, 57, 348-356.

Dunn, J. \& Shatz, M. (1989). Becoming a conversationalist despite (or because of) having a sibling. Child Development, 60, 399-410.

Eisenberg, A. R. \& Garvey, C. (1981). Children's use of verbal strategies in resolving conflicts. Discourse Processes, 4, 149-170.

Garvey, C. (1975). Requests and responses in children's speech. Journal of Child Language, 2, 41-63.

Gearhart, M. (1983). Social plans and social episodes: the development of collaboration in role play. Unpublished doctoral dissertation, City University of New York.

Jacobs, B. S. \& Moss, H. A. (1976). Birth order and sex of sibling as determinants of mother-infant interaction. Child Development, 47, 315-322.

Jones, C. P. \& Adamson, L. B. (1987). Language use in mother-child and motherchild-sibling interactions. Child Development, 58, 356-366.

Matsumori, A. (1981). Hahoya no kodomo e no gengo ni yoru koodoo kisei - yookyuu hyoogen no nichibei hikaku. In F. C. Peng (ed.), Gengo Shuutoku no Shosoo [Aspects of language acquisition] (Hiroshima: Bunka Hyoron), 320-339.

McGrew, W. C. (1972). An Ethological Study of Children's Behavior (New York: Academic Press).

Munn, P. A. (1990). The development of understanding of social rules between the ages of 24 and 36 months. Unpublished doctoral dissertation, University of Cambridge, England.

Newman, D. (1978). Ownership and permission among nursery school children. In J. Glick \& K. A. Clarke-Stewart (eds), The Development of Social Understanding (New York: Gardner), 213-249.

Olson, D. R. (1980). Some social aspects of meaning in oral and written language. In D. Olson (ed.), The Social Foundations of Language (New York: Norton), 90-101.

Rao, C. R. (1973). Linear Statistical Inference and its Applications. Second edition. (New York: Wiley).

Registra General (1971). Census 1971. Great Britain Summary Tables (1\% Sample) (London: Her Majesty's Stationery Office).

Scarr, S. \& McCartney, K. (1983). How people make their own environment: a theory of genotype-environment correlations. Child Development, 54, $424-435$.

Shatz, M. (1978a). Children's comprehension of their mothers' question-directives. Journal of Child Language, 5, 39-46.

$(1978 b)$. On the development of communicative understandings: an early strategy for interpreting and responding to messages, Cognitive Psychology, 10, 271-301.

(1991). Using cross-cultural research to inform us about the role of language in development: comparisons of Japanese, Korean, and English, and of German, American and British English. In M. H. Bornstein (ed.), Cultural Approaches to Parenting (Hillsdale, NJ: Erlbaum), 139-154.

- (1994). A Toddler's Life: Becoming a Person (New York: Oxford University Press).

Shatz, M., Grimm, H., Wilcox, S. \& Niemeier-Wind, K. (1989). The uses of modal expressions in conversations between German and American mothers and their two-year-olds. Paper presented at the Biennial Meeting of the Society for Research in Child Development, Kansas City, April 1989.

Snow, C. E. (1972). Mothers' speech to children learning language. Child Development, 43, 549-565. 
Strayer, F. F. \& Strayer, J. (1980). Preschool conflict and the assessment of social dominance. In D. R. Omark, F. F. Strayer \& D. G. Freedman (eds), Dominance Relations: An Ethological View of Human Conflict and Social Interaction (New York: Gardner), 137-158.

Vaughn, B. E. \& Waters, E. (1981). Attention structure, sociometric status, and dominance: interrelations, behavioral correlates, and relationships to social competence. Developmental Psychology, 17, 275-288. 